\title{
Mudando Paradigmas em Leitura de Textos: a Orquestração do Professor, o Pensar Mlto em Grupo e a Técnica do "Revozeamento"
}

Changing Paradigms in Text-Reading: Teacher's Orchestrated, Group-Think Aloud and “Revoicing” Technique

Vilma LEMOS *

Resumo: Práticas de leitura de textos em português têm sido alvo de muitos pesquisadores. Pesquisas nacionais e internacionais apontam este como um ponto frágil da educação brasileira. Este artigo objetiva mostrar uma mudança de atuação docente, por meio do pensar alto em grupo, um instrumento pedagógico e uma metodologia de pesquisa, aliado à técnica do "revozeamento", cujo objetivo é valorizar as contribuições dos estudantes durante discussão de textos em grupo. Os dados referem-se a uma classe de universitários de Publicidade e Propaganda. Os resultados benéficos traduziram-se em um professor orquestrador das vozes dos alunos, relações menos conflituosas e alunos mais autoconfiantes, reflexivos e críticos.

Palavras-chave: Práticas de leitura. Professor orquestrador. "Pensar alto em grupo".

Abstract: Practices of reading texts in the Portuguese language have been object of study of quite a great deal of researchers. National and international researches indicate this as one of the weak points in Brazilian education. This article aims at showing change in teacher work, by means of group-think aloud, a pedagogical tool and a research

\footnotetext{
* Pós-doutoranda em Linguística Aplicada. Possui doutorado em Linguística Aplicada e Estudos da Linguagem pela Pontifícia Universidade Católica de São Paulo (2005). Mestrado em Língua Portuguesa (PUC/SP, 1988). Contato: vilemos@yahoo.com.br
} 
methodology, in connection with the "revoicing" technique, which aims at valuing students' contributions in group text discussion. The data refer to a class of Publicity and Advertising university students. The beneficial results are represented by a teacher who orchestrates the students' voices, less conflict generating relations and students who are more self-confident, reflexive and critical.

Key-words: Reading practices. Orchestrating teacher. Group-think aloud.

\section{Introdução}

Este artigo registra resultados da reflexão crítica da uma prática docente em leitura de textos publicitários com estudantes universitários de um curso de Publicidade e Propaganda, em aulas de Língua Portuguesa II (Redação e Expressão Oral). Essa prática reflexiva conduziu, gradualmente, ao longo de 3 anos, a uma mudança do paradigma diretivo de atuação em sala de aula para a atuação de um professor "orquestrador", em diálogo com as "vozes" dos estudantes e suas contribuições nas discussões sobre textos publicitários em eventos de leitura.

Para isso, foi necessário deixar de lado a leitura privilegiada de professora-autoridade, considerar a leitura sob a ótica da indeterminação dos sentidos (BLOOME, 1993; ZANOTTO; MOURA, 2002) e, ainda, mudar uma metodologia de ação docente, adotando o "pensar alto em grupo" (ZANOTTO; PALMA, 2008), aliado à técnica do "revozeamento" (O'CONNOR; MICHAELS, 1996).

Um pressuposto norteador de ação docente foi considerar que autor e leitor são sujeitos ativos, em constante diálogo, sendo o texto o lugar de interação. Ao professor cabe o papel de um leitor em diálogo com os leitores-alunos e com o autor. Isso implica entender-se não mais como o construtor privilegiado de sentidos.

A relevância desta forma de atuação docente estende-se tanto para o aperfeiçoamento do próprio professor em serviço, quanto para a formação dos futuros publicitários, que têm seu senso crítico aguçado pela desconstrução reflexiva, em grupo, das peças publicitárias e leituras menos ingênuas desse material. Acrescente-se a isso a percepção da responsabilidade ética na produção de textos da área 
Configura-se, dessa forma, como objetivo deste trabalho, apresentar um paradigma de atuação docente que propiciou mudanças benéficas para a professora no exercício de sua profissão e para os alunos em leitura crítica de texto publicitário, por meio do "pensar alto em grupo" e da técnica discursiva do "revozeamento".

\section{Paradigmas de atuação docente}

Mudança na metodologia da ação docente pressupõe revisão do papel do professor. Por essa razão, apresentam-se dois modelos: o do professor formado segundo a visão tradicional e a nova visão do profissional reflexivo, visto como intelectual crítico e produtor de conhecimento. Em ambos, apresenta-se a forma como a leitura é enfocada.

Como o discurso do professor, um capital simbólico (BOURDIEU, 1996), é legitimado institucionalmente, ficando o aluno como a voz silenciada, buscar o equilíbrio torna-se necessário, com algumas ações. Uma delas refere-se à importância de criar o espaço em sala de aula para trocas entre professor e alunos nos eventos sociais de leitura, quando ambos ganham em aprendizagem, relacionamento e conhecimento (CAMARGO, 1999; SENNA, 1999; PIMENTA, 2002a; 2002b; MARCOVITH, 1998). Isso se torna possível pela reflexão intencional na e da ação do professor (SCHÖN, 2000; PIMENTA; ANASTASIOU, 2002), mobilizado por vontade política de mudança, mesmo considerando as incertezas que mudanças possam provocar no estabelecido.

É desejável, para que isso ocorra, evitar posturas rígidas, dogmáticas, de detentor de conhecimento, para flexibilizar o espaço da sala de aula como democrático, promovendo sua autonomia e a do aluno (ALARCÃO, 1996). Isso poderá despertar o professor para investigador de sua própria prática (MATOS, 2001), gerando conhecimento para si e para seus pares (MOITA LOPES, 2001), possibilitando-lhe entender melhor como os sentidos são construídos socialmente quando se dá voz para o aluno. 


\subsection{O professor no paradigma tradicional}

Nesse paradigma tradicional, o discurso do professor tem mais valor porque legitimado socialmente pelas instituições e a voz do outro (do aluno) tem pouca representatividade. Nessa configuração, a construção social de sentidos não encontrará terreno fértil, uma vez que o aluno é reduzido ao silêncio. O padrão do professor opera pela busca de convergência em leitura, procurando homogeneidade e eliminação de conflitos, o que resulta em comportamento artificial, visto que também nas situações de conflito gera-se sentido. Ignorar isso é ignorar a trama viva da dinâmica social e suas relações e dos processos de construção de sentidos. Conforme diz Camargo (1999, p. 70), o professor deve ter ciência de que "a homogeneidade é ilusória, tendo em vista as diferentes culturas de que são originários os alunos”.

Uma vez que a escola pode ser um espaço privilegiado para interações e negociações em leitura e, consequentemente, para que a aprendizagem ocorra, é preciso que o professor mude seu paradigma centralizador e se torne mediador, por ação intencional, entre o saber dos alunos e o institucionalizado.

Em relação ao ato de ler textos e construir sentidos com alunos, a literatura sobre o assunto e a produção acadêmica recente nas universidades atestam que tem havido mudanças na postura dos professores, embora ainda sejam poucas e não mostrem resultados significativos no plano macrossocial. $\mathrm{Na}$ pesquisa realizada pela Organização para a Cooperação e Desenvolvimento Econômico (OCDE), com jovens de 15 anos, o Brasil ficou em 53. ${ }^{a}$ posição em Leitura, numa escala de zero a mil. Embora tenha saído de 396 em 2000 para 412 (GASPAR, 2010), o país ainda deixa a desejar neste item, há muito ainda por fazer.

Os reflexos disso estão presentes também na universidade. E, mesmo que haja problemas em pesquisas cujos objetivos são avaliar graus de letramento, conforme esclarece Soares (2010), na observação de sala de aula ocorrem grandes desníveis em leitura. Informa a autora: "Os processos de obtenção desses dados apresentam, porém sérios problemas de natureza técnica, conceitual, ideológica e política." (SOARES, 2010, p. 63). Mesmo concordando com a autora, esses aspectos não serão discutidos aqui. 
Ora, se a escola é onde se trabalha o conhecimento (PIMENTA, 2002b, p. 31), e o foco é o aluno, escola e professores precisam de respostas novas.

Posturas tradicionais de professores zelosos de sua autoridade, habituados a guiar alunos, não colaboram senão para manter o silêncio nas práticas de leitura. Mesmo que mudanças tragam mais incertezas, e novas rotas de busca sejam necessárias (CELANI, 2004), os professores devem, nessas circunstâncias de imprevisibilidade, verem-se como aprendizes, conforme destaca Martins (2004, p. 31).

Ao alcançar esse estágio de consciência em relação a si mesmos como professores que também estão em um grupo de aprendizagem, os professores têm que se sentir muito menos seguros de sua bases do que os alunos.

Para que a relação entre professor e alunos seja genuína, nunca deve haver lugar para a autoridade do sabe-tudo, ou para a influência autoritária do que é oficial.

Portanto, mudanças são desejáveis porque é assim que o professor exercita seu papel na construção da sociedade, a bem do ensino, do aluno e de si mesmo num mundo em crescentes e aceleradas transformações e sua renovação passa por posturas metodológicas também renovadas, principalmente se o professor está interessado em formar agentes críticos, hábeis em identificar e desfazer a manipulação presente em textos que circulam socialmente e aos quais os alunos estão expostos cotidianamente.

Essas atitudes poderão contribuir para o avanço nas práticas de leitura e construção de sentidos de forma mais democrática e produtiva em sala de aula, bem como na alteração de eixo em relação ao ser professor num mundo cujos referenciais já não são aqueles em que o docente se formou.

Ressalve-se, entretanto, que não compete apenas ao professor o ônus de resultados oficiais sobre leitura de alunos. Há fatores como o escasso acesso a livros na esfera familiar, a concorrência das novas mídias - para as quais a escola ainda não abriu espaço - e a formação inadequada de professores - que pode ser revertida - mas é preciso reconhecer que mudanças são desejáveis no fazer do docente. 


\subsection{O professor reflexivo e o intelectual crítico reflexivo}

A palavra reflexivo aqui deve ser entendida como "movimento teórico de compreensão do trabalho docente" (PIMENTA, 2002a, p. 18). Inserir-se nesse movimento, implica, para o professor, reformularse e às suas práticas, com uma visão crítica, tornando-se um pesquisador na e da sua ação. É a reflexão sobre a reflexão na ação inspirada em Schön (2000, p. 17). Quando a situação-problema na docência não está no manual, uma forma competente de resolvê-la é pela improvisação, "inventando e testando estratégias situacionais que ele próprio produz".

Pimenta (2002a, p. 22) discute o ensino como prática reflexiva:

O ensino como prática reflexiva tem se estabelecido como uma tendência significativa nas pesquisas em educação, apontando para a valorização dos processos de produção do saber docente a partir da prática e situando a pesquisa como um instrumento de formação de professores em que o ensino é tomado como ponto de partida e de chegada da pesquisa.

Não se está fazendo aqui a apologia do praticismo ou do individualismo, receio de muitos autores que pensam sobre educação, e crítica recorrente ao norte-americano D. Schön - principal formulador da questão do professor reflexivo. Reconhece-se a importância das teorias da educação para uma visão mais ampla e variada sobre o assunto e a inserção do professor num contexto histórico, social e cultural mais amplo, que influencia e reflete na sua formação profissional.

Sustentando esta visão de professor reflexivo, portanto, está a postura consciente e crítica do entorno, não circunscrita apenas ao contexto da sala de aula, porque há contextos institucionais e sociais nos quais as instâncias professor/aluno/ sala de aula se inserem e que as dimensionam pela interação. Por essa razão, não se entenda a reflexão como ação que se reduz a uma sala de aula particular. A sala é o princípio gerador da reflexão política que norteia ações e que deve ser constante e reformuladora para novas situações, já que, sendo dinâmica a vida, por que não a sala de aula e sua prática? Somente a ausência do senso crítico a quereria estática. 
É ainda no contexto social complexo dos tempos atuais que um professor deve ser, acima de tudo, um profissional competente, reflexivo, ético, para que saiba atuar na imprevisibilidade.

A prática reflexiva e crítica do professor por um movimento de transformação dentro desses contextos não deve, portanto, ser individualista, centralizada na aula como lugar de experimentação e investigação, porque seria uma restrição do alcance das mudanças pretendidas, já que a sala de aula não é uma entidade isolada: opera em contexto, absorvendo-o ou refutando-o. O conhecimento de sua realidade, de si mesmo ajudará o professor nas suas intervenções transformadoras, relativizadas por fatores sobre os quais nem sempre tem responsabilidade.

O perfil do professor intelectual crítico reflexivo envolve posturas políticas no coletivo. Parte-se da ação individual, mas dialoga-se com a teoria para dar novos significados à prática de forma que a torne coletiva.

possuir uma atitude investigadora e crítica em relação à prática pedagógica e aos conhecimentos historicamente produzidos e, de outro, a constituírem-se, juntamente com seus colegas escolares ou universitários, como principais responsáveis pela produção de seus saberes e pelo desenvolvimento curricular de sua escola com base na investigação (MATOS, 2001, p. 331)

Por essas razões, propor ações que levem alunos a ler criticamente peças publicitárias, refletir sobre a própria prática, alterar paradigmas de condução de sala de aula são desejáveis para que, efetivamente, seja a sala o espaço de afirmação da voz do aluno sob o olhar cuidadoso e atento do professor, visto como orientador e não centralizador do processo nas atividades de leitura.

\section{0 "pensar alto em grupo" e a técnica discursiva do "revoicing"}

Dois aspectos foram importantes para a mudança de um paradigma de atuação: o "pensar alto em grupo" e o "revoicing". 


\section{1 "O Pensar Alto em Grupo"}

A prática do "Pensar Alto em Grupo", um método introspectivo de pesquisa, tem como referencial o Grupo de Estudos da Indeterminação e da Metáfora (GEIM), da PUC-SP, liderado por Zanotto (1997, p. 13), que define esta prática pedagógica como "evento social de leitura, no qual os leitores, numa interação face-a-face, partilham, negociam, constroem e avaliam as diferentes leituras, e é essa prática de leitura aparentemente simples, que pode ter implicações complexas e relevantes".

Para esse grupo, leitura é uma prática social, na qual se inserem as vozes dos sujeitos, refletindo o contexto social, cultural e histórico, de acordo com a Linguística Aplicada pós-moderna. Portanto, como prática social, o "Pensar Alto em Grupo" é tanto um evento de letramento, em que textos são discutidos, abrangendo aspectos sociocognitivos dos envolvidos, quanto uma prática de letramento, em que modelos ideológicos e culturais estão imbuídos na leitura e escrita durante o evento.

O "Pensar Alto" como instrumento didático aplicado à leitura em sala de aula permite aos alunos "construírem sentidos por si mesmos, o que os torna mais autoconfiantes, reflexivos e críticos" (ZANOTTO, 2008). Assim, as vozes dos leitores são ouvidas e validadas, objetivo principal nesta metodologia, valorizando a subjetividade dos leitores.

$\mathrm{Na}$ aplicação didática, distribui-se um texto para os alunos que, após leitura silenciosa, passam a discuti-lo no grupo, partilhando livremente suas leituras. O professor é apenas orquestrador, mediador das múltiplas vozes. Como instrumento metodológico de geração de dados, gravam-se os eventos de leitura, que, transcritos, são alvos do pesquisador para análise.

\subsection{A técnica discursiva do "revozeamento" (revoicing)}

As práticas de "revozeamento" do verbalizado pelos estudantes têm por base os trabalhos de O'Connor e Michaels (1996). Trata-se de um movimento discursivo promovido intencionalmente pelo professor para encaixar alunos em determinado papel no grupo de discussão. 
Às vezes, os próprios participantes do grupo fazem isso entre si. Segundo as autoras, "rovozeamento" é um tipo especial de reelaboração expressiva (oral ou escrita) da contribuição do aluno realizada por outro participante da discussão (O’CONNOR; MICHAELS, 1996, p. $71)^{1}$. As principais funções do "revozeamento" são a reformulação e a criação de alinhamentos e oposições na argumentação.

$\mathrm{Na}$ reformulação, usa-se, na maioria das vezes, o discurso indireto para fundir a palavra do professor e a intenção do aluno. Essa ação valoriza o aluno como originador intelectual do conteúdo do enunciado "revozeado". Desse modo, o professor usa o enunciado para alinhar os estudantes entre si, trazendo suas contribuições para a discussão, mas também permite ao estudante concordar ou não com a sua fala reestruturada. Se houver concordância, o professor pode usar de resumo, paráfrase, expansão do enunciado para colocar em primeiro plano o aspecto mais significativo do conteúdo trabalhado. Esta é uma forma de legitimar a voz do aluno.

No uso do discurso indireto, o professor coloca o aluno como sujeito de um verbo de fala ou de cognição e o anima, no sentido de Goffman (1984; 1986), na esfera pública e dá crédito às suas contribuições para esclarecer, reestruturar o que disse.

Acrescenta-se à reformulação e ao discurso indireto o uso de marcadores de inferência autorizada, como "Então" (por exemplo, "Então, o que você quis dizer é...).

Cruzam-se aqui as orientações do Pensar Alto em Grupo com as práticas de "revozeamento". Estas, com finalidades múltiplas como ampliar a voz do aluno para o grupo, sustentá-lo como originador de argumento, como levantador de hipóteses, ou, ainda, como forma de confrontar dois argumentos originados no grupo de discussão. Aquelas, como forma de abrir espaço para as vozes dos alunos, numa primeira instância, quando podem verbalizar espontaneamente sobre o texto. Ambas funcionam como práticas que objetivam a formação de leitores capazes de expor raciocínio, argumentos, pontos de vista, com a finalidade de torná-los capazes de ouvir, posicionar-se, refutar a voz

${ }^{1}$... by revoicing we mean a particular kind of reuttering (oral or written) of a student's contribution - by another participant in the discussion. 
do outro, em benefício da formação de leitores críticos. É nesse espaço de diálogo que o professor atua como orquestrador, com atenção redobrada para as manifestações dos alunos.

É bom destacar que a escuta atenta não é tarefa fácil, quer seja para posicionar o estudante como originador de raciocínio, dar-lhe voz maior, quer seja para mudar uma prática consolidada de que só o que o professor diz é que vale. Para Palmer (1998 apud BROOKFIELD; PRESKILL,1999, p. 93), embora não seja uma tarefa fácil, há compensações.

Attentive listening is never an easy task - it consumes psych energy at a rate that tires and surprises me. But it is made easier when I am holding back my own authoritative impulses. When I suspend, for just a while, my inner chatter about what I am going to say next, I open room within myself to receive the external conversation. $^{2}$

\section{A prática em ação: analisando eventos de leitura}

Com a finalidade de mostrar uma mudança de paradigma na atuação docente para ilustrar este artigo, recortes de dois protocolos verbais foram selecionados: um de 2002, com um grupo focal de 8 alunos e outro de 2004 com todos os alunos (25). O primeiro analisado já é resultado de alguma prática intencional da professora, movida pelo espírito de mudança. O confronto com o de 2004 levará às conclusões sobre o que aqui se discute. Ressalve-se que mostrar essa mudança demandaria maior número de recortes de eventos de leitura, no entanto, por limitação de espaço, a opção foi apresentar o recorte maior no final do processo, quando a qualidade dos resultados já eram mais notórios.

${ }^{2}$ A escuta atenta nunca é uma tarefa fácil - consome energia psicológica a um grau que me cansa e surpreende. Mas é mais fácil quando eu seguro meus próprios impulsos autoritários. Quando eu adio, por um momento, a minha tagarelice interior sobre o que vou dizer a seguir, eu abro um espaço dentro de mim para receber a conversa externa. 
3.1 Biscoito Calipso: grupo focal (2002)

A peça publicitária que se segue foi capturada do site do Anuário de publicidade do Clube de Criação de São Paulo e reduzida 50\%. O texto:

\section{"Uma caixa inteira de Calipso? \\ Não vi não."}

Calipso. Biscoito irresistivelmente coberto com chocolate.
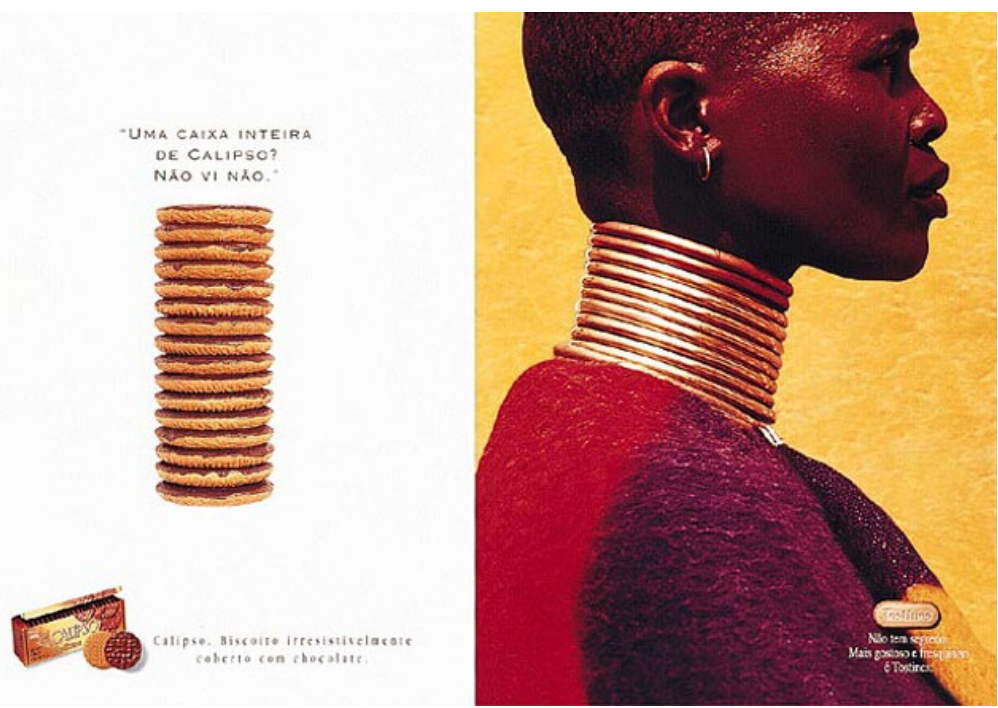

Disponível em: <http://ccsp.com.br/anuarios/pop_pecas.php?id=1610>

Em 82 turnos de fala ${ }^{3}$, houve 6 interferências da professora. A presença da professora ocorre a partir do turno 58 com uma pergunta,

${ }^{3}$ Para Marcuschi, turno pode ser tido como aquilo que um falante faz, ou diz, enquanto tem a palavra, incluindo ai a possibilidade do silêncio (2003, p. 18). 
cujo objetivo era inserir a ética na discussão porque uma fala no turno 38 lhe chamara a atenção:

38 Plínio - Nego brilha.

Os alunos discutiam se a modelo negra estava molhada ou suada, talvez devido ao brilho da fotografia. Havendo ou não intenção preconceituosa na fala de Plínio, a intervenção era propícia para discutir ética e preconceito.

58 Professora: Vocês discutiram alguma coisa ligada à questão ética?

Nos turnos subsequentes ao 38, o grupo conduz a explicação para a resolução (clareza) da fotografia, procurando analogias entre a cor da modelo/ a cobertura de chocolate do biscoito, a posição da caixa do biscoito e as argolas no pescoço da negra. Plínio silencia por 31 turnos, quer porque o grupo tivesse redirecionado para outros sentidos, quer porque ele não se vira ratificado, ou, ainda, como forma de crítica implícita a esse grupo que lhe negara voz.

39 João : É a resolução [da foto].

40 Neide: É a resolução.

46 Daniela: Tem uma ligação entre a bolacha...

47 Guilherme: Tem várias ligações: a bolacha, o pescoço...

48 Daniela: A cor.

49 Guilherme: A cor dela com a cor da bolacha. As cores usadas...

No turno 69, Plínio reaparece e muda de posição, assumindo a voz do grupo, quer pela coerção que dele sofrera, quer para se defender do isolamento.

69 Plínio: Ele usou a mulher porque a mulher é negra. Tem o tom do chocolate, que é a cobertura... 
A professora mobilizou-se para instigar a discussão do preconceito e da ética, mas ainda aparece nas suas perguntas a preocupação em levar os alunos a uma leitura convergente.

63 Professora: Que mais vocês recuperaram nessa [publicidade]? Chegaram a um senso comum em relação à interpretação desse texto?

A tentativa de dar voz aos alunos por meio da técnica discursiva do revoicing (O'CONNOR; MICHAELS, 1996), animando-os (GOFFMAN, 1984; 1986) como originadores intelectuais do conteúdo, ainda é incipiente.

Professora: O que vocês argumentaram em função da questão do preconceito? Houve um grupo que disse que era preconceito. Vocês disseram que não.

Nesse turno, por meio de perguntas, os alunos (Vocês) foram colocados como sujeitos gramaticais; depois a professora usou o discurso indireto e confrontou opiniões, mecanismos da técnica discursiva do revoicing usados intencionalmente. No turno em destaque, o objetivo era fazê-los pensar sobre o preconceito que surgira na discussão devido à cor negra da modelo.

Outra tentativa de orquestrar pelo revoicing aparece no turno 78. O grupo insere na discussão um dado da cultura africana, das mulheres que usavam argolas.

Ocorre interferência da professora, que confronta duas ideias, “apaga" uma não qualificada para a discussão e ratifica a de Plínio que, anteriormente, enunciara um preconceito - "Nego brilha" - e, depois, talvez mobilizado pelo rumo da discussão do grupo, tenha se alinhado a ele.

Ao dar relevância ao alinhamento de Plínio ao grupo, a professora não buscou uma convergência de leitura. Essa ação se deveu a uma mudança - ocasional ou não - de postura em relação ao preconceito por parte do aluno. Daí o aproveitamento da situação para destacar sua ideia positiva. 
Não houve descredenciamento, de início, da fala de João, que seria "apagada" na $2^{a}$ oração. Houve o cuidado de justificar a razão de dar uma voz mais "alta” a Plínio. O revoicing de animação foi utilizado, já que Plínio assimilara uma ideia do próprio grupo (relação foto da negra/ cor do chocolate). Com esse movimento conversacional, dirigindo o enunciado do aluno, a professora encaixou-o no papel de pensador no grupo.

A voz geral do grupo parece ficar marcada na fala de Guilherme que, após associar a cor da modelo com o chocolate, responde à pergunta do turno 80 sobre a não existência de preconceito na propaganda. Faz eco à sua fala o aluno João, no turno 82. Também as vozes da sala partilham essa visão.

80 Professora: Então, o senso comum aqui é que não tem preconceito?

81 Guilherme: Não, não tem.

82 João: Não, não tem.

Todos: falas simultâneas de concordância de que não há preconceito: "Não, não...".

Destaca-se a voz indutora da professora, que trabalha pelo senso comum, mesmo com a intenção de trabalhar o preconceito. Esses recortes correspondem às melhores atuações da professora nesse evento, mas ainda ocorrem hesitações e direcionamentos.

\subsection{Biscoito Calipso: 2004}

Dois aspectos destacam-se numa análise geral desta turma: uma participação mais atuante da professora no grupo, marcando uma dinâmica diferenciada em relação às discussões anteriores, e a técnica de resumir a leitura do grupo em determinado ponto da discussão para que os alunos pudessem avaliar a construção de sentidos da equipe. Nesse aspecto, talvez haja um desdobramento em relação à proposta do pensar alto em grupo do GEIM, embora as motivações sejam as mesmas: criar espaço para as verbalizações dos alunos.

O uso de perguntas foi uma estratégia discursiva, mas não deve ser entendido como a técnica da IRA (iniciação, resposta, avaliação), 
muito comum para cumprir uma agenda. Isto porque a indeterminação dos sentidos já estava consolidada nas ações da professora, bem como a compreensão da leitura como evento social e dialógico para a construção negociada de sentidos entre os pares, prática muito mais democrática, menos mecânica do que a IRA.

As sequências perguntas-respostas buscam encorajar a participação dos alunos para que explicitem seus argumentos, discutam preconceitos manifestos pela linguagem, a fim de refletirem sobre suas afirmações, bem como envolvê-los na atividade e dar-lhes voz no grupo social.

No primeiro turno, a professora engaja os alunos na prática de discussão em grupo, criando um quadro de participação que lhes permite assumir papéis e responsabilidades.

1 Professora: Então, nós estamos trabalhando a leitura de uma peça publicitária. O que vocês acharam, o que chamou a atenção, o que foi significativo na composição dessa peça publicitária? Podem falar à vontade.

$\mathrm{O}$ aluno Abel percebe a analogia entre a modelo e o biscoito, mas diz que não lhe desperta a vontade de comer. A aluna Eloísa concorda com ele.

6 Professora: Eles disseram que esta peça publicitária não desperta a vontade no consumidor de comer. O que é que você acha disso? Não desperta, desperta, por quê? Concorda?

O revoicing pelo discurso indireto amplia a voz dos dois alunos para o grupo.As perguntas abrem a discussão em relação ao proposto. Outro aluno ratifica a mesma leitura, justificando que é nojento, meio esquisito o biscoito no pescoço da mulher, que parece suada. $\mathrm{O}$ tema do preconceito é inserido pela professora, também sob forma de pergunta.

8 Professora: É preconceituosa essa visão dele ao dizer que parece suada, é nojento? 
A resposta é assertiva por parte de Paolo, mas, para Márcia, é questão de não combinar.

A professora acolhe a palavra combina e pede explicação para a autora intelectual do enunciado, além de "amarrar" outro aluno (Nicola), chamando-o a participar do esclarecimento.

11 Professora: Se esta mulher não combina, você deve ter observado alguma coisa. Você pode dizer, ou o seu companheiro aqui, que é o .... ?

12 Nicola: Nicola. Eu acho que eu não comeria um negócio assim, parecido com um pescoço de uma mulher.

Apesar de a professora insistir no porquê, permanece o fato de "não combinar". Como surge um dado novo no grupo pelo viés cultural das argolas/ biscoito e uma generalização imperfeita (Todo mundo conhece...), a professora optou por explorar esse hábito muito comum de generalizar sem ter argumentos. Novamente acolhe a expressão usada pelo aluno, repetindo-a e questiona.

16 Antônio: Uma cultura que já existe. Eles tentaram igualar com biscoito porque todo mundo conhece pessoas que têm essas gargantilhas.

17 Professora: Todo mundo conhece?

E o aluno prontamente retifica, delimitando o alcance de sua afirmação:

18 Antônio: Não, muita gente conhece.

Nos próximos turnos, a professora faz eco às vozes dos alunos, ora recolhendo trechos de suas falas e deixando o pensamento inconcluso, ora voltando a questionar, até que eles esclareçam o que pretendem dizer, orientada pela ótica da indeterminação dos sentidos.

20 Antônio Não, já viram uma imagem assim...

21 Professora: Uma imagem... 
22 Antônio: ... então sabem que existem lugares [em] que existem pessoas que usam isso no pescoço

23 Professora: Em que aspecto essa imagem tem a ver com a peça publicitária?

24 Antônio: É, eles tentaram causar uma espécie de igualdade, de semelhança do formato da embalagem do biscoito com as gargantilhas.

Em (24), a ideia já se tornou mais clara e completa na expressão de Antônio, por meio de um processo metafórico, embora já no turno (15), outro aluno, Gil, já houvesse dito a mesma coisa.

Nesse ponto da discussão, havia duas leituras - do viés cultural e do asco, por isso o uso do revoicing para confrontá-las, solicitando a Antônio que argumentasse, animando-o como o autor intelectual e ampliando sua voz para toda a sala, a fim de que se alinhasse com o grupo.

27 Professora: Antônio, você acha que isso causou um efeito produtivo? Os meus meninos da ala da esquerda aqui julgaram que esta imagem provoca asco. Você acha pertinente, você acha legal, você discorda, concorda?

Na resposta de Antônio, está latente o publicitário preocupado com marketing.

30 Antônio: Pra vender, não foi legal. Eu acho que não foi legal.

O revoicing, por meio do discurso indireto, coloca o aluno como sujeito do enunciado,

para ampliar a voz de Antônio para a sala e, assim, provocar a discussão.

31 Professora: O Antônio disse que não foi legal, para efeito de venda, associar a imagem desta, parece-me uma negra, com as argolas no pescoço e a peça publicitária ligada ao biscoito. Você quer falar? 
Com a pergunta final desse turno, outro aluno é engajado para dar explicações, concordando ou discordando de Antônio.

32 Cristian: Achei legal a sensação, que, no caso, tem o chocolate junto com a bolacha, daí, da cor da pessoa, mas a argola deu essa sensação. Sem contar o amarelo de fundo, que estimula a vontade de comer.

Cristian discorda e acrescenta um dado novo (cor como estimulante do apetite). A pergunta seguinte foi uma forma de levar esse aluno a apresentar suas razões, argumentar.

33 Professora: E você acha produtivo, você acha que causa desejo nas pessoas, foi pertinente, causa surpresa?

34 Cristian: Causa surpresa. Eu acho que chama um pouco a atenção, acho que tem um pouco de humor também.

35 Professora: E qual é o humor que você observa aî?

36 Cristian: Acho que, pela fonte usada, ela tem um lance um pouco de humor, tanto na fonte usada para escrever "uma caixa inteira de calipso? Não vi não". Eles acham um pouco de sacada de humor. Sem contar a assimilação...

Intencionalmente ou não, no t. 34, o aluno "recolhe" a última palavra (surpresa) da fala da professora e a usa na sua resposta, acrescentando um dado novo: o humor. Aproveitando a palavra-chave (humor), a professora dá-lhe oportunidade de esclarecer o raciocínio, porque não tinha certeza da clareza de sua explicação. Novamente o revoicing é acionado, colocando-o como sujeito da informação para ratificar ou não a compreensão de sua fala.

37 Professora: Então você menciona a questão da linguagem trabalhada para provocar humor, associada ao produto. É isso?

Posteriormente, o aluno informou que era o tremido das letras que poderia provocar humor, mas, no caso, fora apenas a qualidade defeituosa da xerox. O preconceito aparece e, como não houve manifestações, o revoicing foi usado, devolvendo a pergunta para a sala, 
para confrontar opiniões, uma forma de estimular o debate, expondo os alunos a uma situação de conflito para que se posicionassem reflexivamente.

82 Professora: Bom, o Rodrigo e alguns verbalizaram a questão do preconceito. É muito forte a uestão do preconceito aí, minha gente?

Com isso, foi possível recuperar outras vozes desse fórum de discussão que não se manifestavam (foram 22 turnos, sendo 5 de Henrique, 6 de Rodrigo, 1 de Jaiza e 10 da professora). Este evento se estende até o turno 159. Por razões de espaço, não serão analisados.

\section{Considerações finais}

Agir com flexibilidade é a primeira ação do professor que se propõe mudar, porque o professor diretivo não permite espaço para os alunos e suas manifestações espontâneas. Resulta que as leituras e construção de sentidos em sala de aula podem reduzir-se a cumprir agenda tanto do lado do professor quanto do aluno, cada um em seu espaço: o professor faz perguntar fechadas, o aluno responde monossilabicamente e a discussão não avança. Nesse sentido, o "pensar alto em grupo" e a técnica discursiva do "revozeamento" (revoicing) são de grande utilidade, porque alteram essa configuração.

O "Pensar Alto em Grupo" estimula e orienta para a escuta atenta, sensível da voz do outro, acolhe a indeterminação dos sentidos e propõe leitura como conversa social, espontaneamente.

A escuta sensível auxilia na utilização da técnica discursiva do revoicing, quando o professor, usando o componente de reformulação por meio do discurso indireto, funde sua palavra e a intenção original do aluno, animando-o como o autor de um dado conteúdo reformulado, atribuindo um alcance maior à sua voz no espaço de discussão e, ainda, possibilita criar alinhamentos e oposições na argumentação. Também o marcador de inferência autorizada (como então) na reformulação do conteúdo do aluno, animado pela voz do professor, permite-lhe concordar ou discordar do conteúdo "revozeado", uma oportunidade para que o senso crítico aflore. 
Todas essas formas de ação contribuíram para a mudança de um paradigma de atuação docente. Não é um caminho ameno. Exige prontidão do professor em tempo integral para mobilizar o grupo a participar, abdicação do senso comum e interesse real de mudanças. Convive-se com a incerteza e com o risco.

$\mathrm{Na}$ mudança de paradigma, não se trabalha pela homogeneização da leitura do grupo, porque respeita as diferentes formações culturais dos alunos e o seu conhecimento prévio. A opção por um profissional reflexivo e crítico não se esgota aqui, já que é preciso aperfeiçoamento constante.

\section{Referências}

ALARCÃO, I. Ser professor reflexivo. In: - (Org.). Formação reflexiva de professores: estratégias de supervisão. Portugal: Porto, 1996.

BLOOME, D. Necessary indeterminacy and the microethnographic study of reading as a social process. Journal of Research in Reading, University of Massachusetts, v. 16, p. 98-111, 1993.

BOURDIEU, P. A economia das trocas lingüisticas: o que falar quer dizer. São Paulo: Edusp, 1996 [1982].

BROOKFIELD, S.D.; PRESKILL, S. Discussion as a way of teaching: tools and techniques for democratic classrooms. São Francisco: JosseyBass Publishers, 1999.

CAMARGO, J.S. Interação professor-aluno: a escola como espaço interativo. In: MARTINS, J. B. et al. (Orgs.) Na perspectiva de Vygotsky. São Paulo: Quebra Nozes; Londrina: CEFIL, 1999.

MARTINS, J.B. (Org.). Na perspectiva de Vygotsky. São Paulo: Quebra Nozes; Londrina: CEFIL, 1999.

CELANI, M.A.A. Culturas de aprendizagem: risco, incerteza e educação. In: MAGALHÃES, M.C.C. (Org.). A formação do professor como um profissional crítico. Campinas: Mercado de Letras, 2004. 
GASPAR, M. Na turma dos piores. Veja, São Paulo, a. 43, n. 50, ed. 2195, p. 142-143, 15 dez. 2010.

GOFFMAN, E. Forms of talk. 2. ed. Philadelphia: University of Pennsylvania Press, 1984.

. Frame analysis. Cambridge, MA: Harvard University Press, 1986 [1974].

KLEIMAN, A. Texto \& leitor: aspectos cognitivos da leitura. 2. ed. Campinas: Pontes, 2000.

MARCOVITCH, J. A universidade impossivel. São Paulo: Futura, 1998.

MARTINS, J.B. Psicologia da aprendizagem: uma abordagem fenomenológica. In: MAGALHÃES, M.C.C. (Org.). A formação do professor como um profissional crítico. Campinas: Mercado de Letras, 2004.

MARCUSCHI, L.A. Análise da Conversação. São Paulo: Ática, 2003.

MATOS, J.C. Professor reflexivo: apontamentos para o debate. In: GERALDI, C.M.G.; FIORENTINI, D.; PEREIRA, E.M.A. (Orgs.). Cartografias do trabalho docente. Campinas: Mercado de Letras, 2001.

MOITA LOPES, L.P. Oficina de Lingüistica Aplicada. 2. ed. Campinas: Mercado de Letras, 2001.

O'CONNOR, M.C.; MICHAELS, S. Shifting participant frameworks: orchestrating thinking practices in group discussion. In: HICKS, D. (Ed.) Discourse, learning and schooling. Cambridge: Cambridge University Press, 1996. p. 63-103.

PIMENTA, S.G. Professor reflexivo: construindo uma crítica. In: .; GHEDIN, E. (Orgs.). Professor reflexivo no Brasil: gênese e crítica de um conceito. São Paulo: Cortez, 2002a. p. 17-52.

PIMENTA, S.G. De professores, pesquisa e didática. Campinas: Papirus, 2002b. 
PIMENTA, S.G.; ANASTASIOU, L. G.C. Docência no ensino superior. São Paulo: Cortez, 2002. v. 1.

SCHÖN, D.A. Educando o profissional reflexivo: um novo design para o ensino e a aprendizagem. Trad. Roberto Cataldo Costa. Porto Alegre: Artmed, 2000.

SENNA, L.A.G. Letramento ou leiturização? O sócio-interacionismo na Lingüística e na Psicopedagogia. In: CONGRESSO DE LEITURA DO BRASIL, 12., 2000, Campinas. Anais... Campinas: Associação de Leitura do Brasil, 2000. p. 3203-3225.

SOARES, M. Letramento: um tema em três gêneros. 4. ed. Belo Horizonte: Autêntica, 2010.

ZANOT'TO, M.S. A leitura como evento social para um enfoque humanístico do ensino de línguas. In: CONGRESSO DO FEDERATION INTERNATIONALE DES PROFESSEURS DES LANGUES VIVANTES - FIPLV, 19., 1997, Recife. Livro de Resumo. Recife: FIPLV, 1997. p. 147.

- As múltiplas leituras da metáfora em sala de aula: uma complexidade pedagógica e teórica. Relatório de Pesquisa. 2008.

; MOURA, H.M.M. Indeterminacy and negotiation. In: VERSCHUREN, J.; ÖSTMAN, J-O.; BLOMMAERT, J.; BULCAEN, C. (Eds.). Handbook of pragmatics. Amsterdam/ Philadelphia: John Benjamins, 2002.

; PALMA, D.V. Opening Pandora's box: multiple readings of a metaphor. In: .; CAMERON, L.; CAVALCANTI, M. (Eds.). Confronting metaphor in use: an applied linguistic approach. Amsterdam: John Benjamins, 2008. 